\title{
BUSINESS AND TRUTH. AN ETHICAL ANALYSIS OF HONESTY IN ADVERTISING
}

\author{
Dragoș BîGU ${ }^{a *}$ Mihail-Valentin CERNEA ${ }^{b}$ \\ ${ }^{a, b}$ Bucharest University of Economic Studies, Romania
}

\begin{abstract}
In this paper the moral viability of the reasonable consumer standard as applied to cases of deceptive behaviour in the advertising industry. The paper is structured into two main sections. The first provides a short lit review concerning the kinds of deceptive techniques used in advertisments around the world, while trying to underline the morally dilemmatic issues associated with them. The second discusses the moral implications of the reasonable consumer standard in light of the difficulties ineherent in defining what reasonable actually means in practice.
\end{abstract}

KEYWORDS : advertising, business ethics, deception, reasonable consumer standard

\section{INTRODUCTION}

In 2013, Red Bull GmbH faced a lawsuit for false advertising that ended with a 13 million \$ settlement to New York resident Benjamin Careathers, a customer that was disappointed that its famous drink did not actually give him the iconic "wings" of its advertising campaigns. This case is interesting not just from the standpoint of the legal scholar, but it also raises interesting ethical questions about the moral responsibility of both advertisers and consumers when it comes to the truthfulness or untruthfulness of marketing communication.

This paper aims to approach this problem by considering how the reasonable consumer standard fares from a moral standpoint in providing moral clarity to dilemmatic situations. To do this, first we provided a short literature review on the typologies of deception in advertising, highlighting the cases which produce moral conundrums of conflicting principles and values. The second main section of the paper tries to underline the problems the reasonable consumer standard faces when dealing with the situations outlined in previous section. The paper ends with conclusive remarks the focus on a comparison with the ignorant consumer standard.

\section{TAXONOMIES OF DECEPTION}

Deceptive advertising represents a difficult challenge for both the regulator and the moral theorist, as some of the techniques used by marketers who see to deceive consumers elude legal frameworks and generate thorny moral dilemmas. This section of our paper is concerned with marketing deception typologies and the cases in which they give rise to ethical conundrums.

In the study of deception in advertising the legal issues involved have been the main theoretical driver behind scholar's efforts to offer up clarifying cartographies of the kinds of deceptive tactics employed by companies and ad agencies (Docan-Morgan, 2019, 821-822). One of the first forays into this domain is due to Gardner (1975) which classifies deceptive claims into three main categories: the unconscionable lie, claim-fact discrepancy and claim-belief interaction. If the claims made in an advertisement are completely false Gardner maintains that marketer is guilty of an unconscionable lie.

\footnotetext{
* Corresponding author. E-mail address: dragos.bigu@man.ase.ro
} 
Interestingly, for Gardner, omission of information can be unconscionable when it chooses to hide information that could significantly alter consumer behavior. One other important aspect of this kind of obvious deception is that the claimed benefits for the consumer must remain actually unattainable even if we were to qualify the information presented for the lie to be unconscionable. Otherwise, it is what the author calls a claim-fact discrepancy in which qualifying statements would bring the information communicated to the potential clients back to the reality of the product. The third class of deceptive practices is the claim-belief interaction in which advertisers try to build on existing social attitudes and beliefs to induce false beliefs about the promoted good or service to the audience. In this case there is no false information presented, only statements meant to interact with the consumer's cultural or social background to form an inaccurate image of the product's capabilities. Xie and Boush (2011) offer an alternative to Gardner's view, classifying deceptive messages as: (i) falsities - whose untruthfulness can be independently verified; (ii) omissions - hiding relevant information about the product; (iii) implication - misleading the public by encouraging wrong inferences that some property or properties of the good being advertised.

This kind of tripartite classification can be useful for the regulator whose aims of finding common ground between business and consumer are inherently more limited. The more granular approach of ethical analysis with its more ambitious goal, that is to provide a framework that could help determine all instances of immoral behavior in the advertising industry, requires a different angle of approach. Shaw (2010) provides a taxonomy of deceptive techniques that emphasizes linguistic, epistemic and psychological factors involved in misleading advertisements. In their objective to attract the consumer, "advertisers are prone to exploit ambiguity, conceal facts, exaggerate, and use psychological appeals”.

Ambiguity is a linguistic property that refers to terms and expressions that have multiple meanings (not to be confused with vagueness - terms and expressions that have an imprecise extension). It is useful for advertisers as it allows them to simply imply false information with plausible deniability. Furthermore, both the regulator and the ethicists will find it hard to navigate the murky waters of socalled weasel words like "help", "as much as", "can be”, etc., which foster hard ethical dilemmas (Shaw, 2010, 236-237). How much performance should be expected of a product which "helps" with memory? How much would one actually save when the sale goes "up to" $80 \%$ ? It is not entirely clear how much information can a reasonable consumer gather from ambiguous contexts, not to mention a more ignorant one. This is why it can be quite difficult to judge whether a piece of advertising that relies on ambiguity is misleading in a morally relevant way.

Shaw underlines the fact that concealment of facts involves either omission or distraction - the important aim is to hide information from the view of the consumer, information that would affect consumer perception on the product's quality or performance (Shaw, 2010, 237). At first glance, concealment of facts may not seem morally dilemmatic, as the intention of the advertiser is quite obvious. Looking at this issue more closely, defining the notion of "relevant information" in the context of commercial is actually more difficult than it may seem. Should car makers inform the audience in their every ad of the relationship between fossil fuels and climate change? Should TV spots about pharmaceutical products state clearly literally all the possible side-effects, no matter their chance of occurrence? The difficulty of this type of questions is compounded by the material conditions of advertising, especially the time constraints that advertisers must meet when communicating with the consumer.

Another way in which advertisers deceive is exaggeration, which Shaw defines as "making claims unsupported by evidence" (Shaw, 2010, 238). Simply put, we are referring to ads that oversell the properties of the goods or services advertised - examples include anti-ageing claims for cosmetic products or "nine out of then experts recommend" types of claims. While exaggerated claims that take the form of what Gardner called unconscionable lies are not difficult to analyze from an ethical standpoint, the fine line between actual deception and potentially harmless puffery. Puffery is "the marketplace term for what elsewhere would simply be called an opinion statement, expressing the 
seller's evaluation of the advertised item” (Preston, 1996, 12). It refers to claims that promote a product using subjective statements that avoid mentioning explicit facts, a practice also named "seller's talk": "my product is the best on the market", "all you need is in this chocolate bar", etc. (Docan-Morgan, 2019, 823). Technically, puffery is harmless because it is assumed that both advertisers and consumers are in “on the game” and that consumers won't base their purchase decisions on claims presented in this way. The ethical difficulties here stem from two sources. Firstly, given the subjectivity of the terms and statements used, there is no easily ascertainable falsity involved. Secondly, the harmless claim of puffery is made in a consequentialist moral framework, but this makes it vulnerable to new information - puffery is harmless only if consumers don't get harmed, that is they really don't take the advertised claims as truthful. Preston counteracts this claim, presenting a survey in which around $50 \%$ to $60 \%$ percent of consumers questions judge common puffery as true or partly true (R.H. Bruskin Associates, 1971 apud Preston, 1997, 180-181). This is why puffery can create situation where malintent is difficult to prove, but some harm can be ascertained, calling into question the border between consumer rights and consumer responsibilities. Morally questionable psychological appeals are involved in "ads that rely extensively on pitches to power, prestige, sex, masculinity, feminity, acceptance, approval, and the like” (Shaw, 2010, 240). While not obviously immoral, commercials that use such techniques do rely on psychological vulnerabilities that most of the humans that happen to be their intended consumers share. Do the consumers have a right to be protected from claims meant to bypass their rational filter? Some authors maintain that psychological appeals are not actually a technique in and of itself, but rather the resulting phenomenon of the fact both advertisers and consumers are human beings that have in common the same basic needs and wants - an unavoidable fact of a marketplace populated by the same species (Shaw 2010, 240). The epistemic minefield between stimulus and behavior alongside the recurring difficulty to prove intentional deception make ads like these difficult to analyze from a moral standpoint, but also difficult to regulate effectively in the non-ideal world.

Most regulators rely on the assumption that the consumer is reasonable in most cases and can generally differentiate between deception and truth except in clear cut cases of malfeasance. Prudentially speaking, this assumption might prove useful for the constitution of legal frameworks, but a more fine-grained ethical analysis could show that not all applications of this standard may result in morally sound judgements, for reasons that we are about to explore in the next section.

\section{REASONABLE CONSUMER ETHICS}

The main piece in the legal, and sometimes ethical, assessment of advertising is the reasonable consumer standard, according to which an ad is deceitful if it misleads a reasonable and averagely informed person. This criterion is used in jurisprudence in order to settle false advertising lawsuits. As an alternative standard, ignorant person standard, according to which uninformed and careless persons who are deceived should also be protected. From a legal point of view, reasonable consumer standard is preferrable, at least from a cost-efficiency perspective. Since any legal enforcement procedure requires a cost and since we can accept that advertising as a whole is beneficial for society and morally acceptable, it is important to confine regulations to practice that are harmful to society; the ignorant consumer standard would excessively punish actions that do not have significant negative effects. Furthermore, an ignorant person standard may be seen as impeding companies' freedom of speech. (Preston, 1974, 133). However, it might be argued that the reasonable consumer standard is not sufficient from an ethical perspective.

First, sometimes advertisers use deceptive strategies that cannot mislead reasonable people, but still mislead intentionally "unreasonable" persons, as judged by responsible institutions. Can we argue that such commercials are morally acceptable? A way to do this would be to state that in such cases deceived consumers are partly responsible for being misled. Even if this is the case, this does not 
alleviate advertiser's responsibility (Saul, 2012, 5). In order to see this, let's take a situation in which a thief steals from a negligent person, who does not take care of her belongings. In the same way, the victim is partly responsible for being negligent. Anyway, his/her negligence in itself does not alleviate robber's responsibility. This is true for two reasons. First, the robber's intention is precisely the same in both cases - stealing, and secondly, the reason for which the s(he) chooses a careless victim is not a moral one: s(he) merely wants to rob someone more easily. In the same time, at least in some cases, advertisers mislead intentionally ignorant people and choose to use mildly instead of strongly deceptive strategies only because thus is easier to avoid legal sanctions. However, there might be cases when some persons misapprehend the message of a commercial and advertisers do not deceive them intentionally. In such cases, advertisers can be responsible for negligence, but they are to blame in a lesser degree.

Another factor that might be important in order to assess advertisers' blame is how relevant the piece of information that is wrongly understood by the consumer is for his/her purchasing decisions. For instance, a Romanian commercial for a bank was withdrawn for misleading consumers in believing that the voice of an actor who plays Constantin Brâncuși, as well as his words, are original. Even if the commercial is indeed misleading, the act of deception is not very relevant, since the voice and words in the video doe not contribute significantly to buyers' decisons.

The second problem with reasonable consumer standard is that there is not a clear-cut line between ads that are acceptable from the point of view of this standard and those that are not acceptable, because It is unclear what epistemic expectations are implied by the concept of being reasonable. In a court case (Becerra v. The Coca-Cola Co.), The Coca Cola Company was sued over its Diet Coke labelling. The plaintiff accuses that the Diet Coke label is misleading, since the drink is not recommended in a diet, as its name induces, because "nonnutritive sweeteners like aspartame interfere with the body's ability to properly metabolize calories, leading to weight gain and increased risk of metabolic disease, diabetes, and cardiovascular disease.” (Becerra v. The CocaCola Co., 2).

However, Judge Alsup stated that "reasonable consumers would understand that Diet Coke merely deletes the calories usually present in regular Coke" (Becerra v. The Coca-Cola Co., 5). Is it true that the Diet Coke label does not create legitimate expectations that the drink can be used in a diet, in the sense that water, for instance, can be used? Since the result of this study was not generally known and since the label uses the word Diet, not Zero, one can argue that a reasonable consumer would understand more that merely the fact that the product has zero calories, namely that Diet Coke does not have a negative effect in a diet. In such cases, companies take profit from the fact that reasonable expectations cannot be clearly defined, which is morally dubious.

An observation is worth making. In his decision, Judge Alsup said that "Such advertising cannot be said to imply that a product will cause weight loss without regard to exercise and nutrition" (Becerra v. The Coca-Cola Co., 6). and this is undoubtedly true, since a reasonable consumer should know that such a product does not exist, all the more so as diet sodas are not weight loss products. However, this does not prove that a reasonable consumer cannot expect that diet sodas are neutral, i.e. they do not have a negative effect in a diet and the referred scientific studies show that this expectation is not met.

In the last part of this section, we will briefly examine a particular kind of advertisement, in order to show how vague, the reasonable consumer standard is. We will focus on the before-after advertisements for weight loss products, which shows two pictures of a person: before and after using a weight loss product, in order for the consumer to notice the huge difference brought by the promote product. It is not clear at all what precisely the information content of such an advertisement is. We can safely accept that a reasonable person would understand that the two pictures are the real (not photoshopped) pictures of the same person, who used the promoted product. But maybe the posture is better in the before picture. Even more important, what other things the model did in the interval between the two pictures? Did s(he) keep diet? Did s(he) 
exercise? Is the model a typical case or an exceptional one? Such information is not usually present in advertisements and consequently the reasonable expectations implied by it are not clear at all. The problem becomes even more complex when the message is supported by a scientific study. Is that study scientifically valid? Is its methodology acceptable? What are more precisely its conclusions? Such questions remain often unanswered in advertisements and the use of scientific studies can be misleading (De Lange, 2006, 190-196).

\section{CONCLUSION}

One other attempt to make sense of the moral pitfalls specific to deceptive advertising is to appeal to one type or other of the ignorant consumer standard, the idea that it is not enough to outlaw marketing techniques that deceive the reasonable consumer, but there is a moral obligation to protect those of us that can be influenced more easily. The problem of defining morally relevant ignorance is as difficult as that of the reasonable consumer, but the fact a strict application of this option would result in considering all advertisement immoral and calling for its banishment. This is why the ignorant consumer standard seems incompatible with public policy.

As such, we believe that a better articulation the notion of reasonable consumer remains a proper research goal of social scientists and philosophers alike, as it could be one important way to bring moral clarity into the realm of deceptive advertising.

\section{REFERENCES}

de Lange, R. (2016). Misleading Advertising: A Case Study of a Marketer's 'Prescribed by Doctors’ Slogan. Critical Arts: South-North Cultural and Media Studies, 30:2, 187-199.

Docan-Morgan, T. (Ed.). (2019). The Palgrave Handbook of Deceptive Communication. New York: Palgrave Macmillan.

Gardner, D. M. (1975). Deception in Advertising: A Conceptual Approach: Deception in advertising needs further definition and procedures for measurement-Gardner's conceptual approach offers suggestions for both. Journal of Marketing, 39(1), 40-46.

Preston, I. L. (1974). Reasonable Consumer or Ignorant Consumer? How the FTC Decides. Journal of Consumer Affairs, 8(2), 131-143.

Preston, I. L. (1997). The Great American Blowup: Puffery in Advertising and Selling. Madison, WI: The University of Wisconsin Press.

Saul, J. (2012). Just Go Ahead and Lie. Analysis, 72(1), 3-9.

Shana Becerra vs. The Coca Cola Company. Retrieved 1 November 2020, from https://www.foodlitigationnews.com/wp-content/uploads/sites/36/2018/03/Becerra-v.-CocaCola-Company-Order-re-MTD.pdf

Shaw, W. H. (2010). Business Ethics: A Textbook with Cases. Boston, MA: Cengage Learning.

Xie, G. X. \& Boush, D. M. (2011). How Susceptible are Consumers to Deceptive Advertising Claims? A Retrospective Look at the Experimental Research Literature. The Marketing Review, 11(3), 293-314. 